\title{
Hallazgos clínico-patológicos compatibles con intoxicación con ionóforos en búfalas: primer reporte en Argentina
}

\author{
Bence, A.R. ${ }^{1,2}$; García, J.1,3; Fernández, E. ${ }^{1}$; Morrell, E. ${ }^{1}$; Cantón, G. ${ }^{1}$ \\ ${ }^{1}$ Instit. Nac. Tecnol. Agrop. (INTA), Balcarce, Argentina. ${ }^{2}$ Área Patol. Dep. Fisiopat. Facult. Cs. Vet. \\ Univ. Nac.Cent. Pcia. Bs.As., Tandil, Argentina. ${ }^{3}$ Activ. privada. \\ E-mail: canton.german@inta.gob.ar
}

\begin{abstract}
Resumen
Bence, A.R.; García, J.; Fernández, E.; Morrell, E.; Cantón, G.: Hallazgos clínico-patológicos compatibles con intoxicación con ionóforos en búfalas: primer reporte en Argentina. Rev. vet. 29: 2, 79-82, 2018. Se describe un presunto caso de intoxicación con ionóforos en búfalas de un tambo de la Provincia de Buenos Aires, Argentina, las cuales habían consumido pasturas y ración comercial formulada para bovinos en ordeñe, conteniendo monensina. Murieron 5 de las 50 búfalas en ordeñe, manifestando taquipnea, disnea, sialorrea, decúbito y muerte. Durante la necropsia se observó hidrotórax, ascitis, hígado con puntillado hemorrágico, edema en vesícula biliar, duodeno y diafragma, así como coloración blanquecina en miocardio. Microscópicamente se evidenciaron miocarditis y miositis necrotizante no supurativa, hepatitis centrolobulillar necrotizante y edema pulmonar severo. La actividad de las enzimas creatinfosfoquinasa y aspartato amino transferasa estaba elevada en animales muestreados al azar. Los datos anamnésicos y clínico-patológicos fueron suficientes para determinar a la intoxicación por ionóforos como el diagnóstico presuntivo de esta mortandad, siendo éste el primer reporte en búfalos de Argentina.
\end{abstract}

Palabras clave: búfalos, intoxicación, ionóforos, histopatología, Argentina.

\begin{abstract}
Bence, A.R.; García, J.; Fernández, E.; Morrell, E.; Cantón, G.: Clinical-pathological findings compatible with intoxication with ionophores in buffaloes: first report in Argentina. Rev. vet. 29: 2, 79-82, 2018. A presumptive ionophore intoxication in a water buffalo dairy herd from Buenos Aires Province, Argentina, is presented. Buffaloes were grazing pastures and were supplemented with a pelleted ration formulated for dairy cattle, that included monensin in its composition. Five out of 50 lactating buffaloes showed tachypnea, dyspnea, sialorrhea, sternal decubitus and death. During post mortem examination hydrothorax, ascites, hemorrhagic centrilobular hepatitis, edematous thickening of the gallbladder, duodenum and diaphragm muscle and light-colored areas in the myocardium, were observed. Microscopically, moderate multifocal non-suppurative necrotizing myocarditis and myositis, severe centrilobular necrohemorrhagic hepatitis and severe pulmonary edema, were found. CPK and AST enzyme activities were significantly elevated in randomly samples buffaloes. Information from anamnesis together with clinicopathological findings are in concordance with natural and experimental ionophore poisoning. This is the first report of toxicity in water buffaloes in Argentina, a highly susceptible animal species to ionophores poisoning.
\end{abstract}

Key words: buffaloes, poisoning, ionophores, histopathology, Argentina.

\section{INTRODUCCIÓN}

La cría de ganado bubalino viene desarrollándose en Argentina desde la década de 1970, cuando se introdujeron los primeros ejemplares. La producción nacional de leche de búfalas se inició en el año 1992, ubicándose los primeros tambos en las provincias de Corrientes y Santa Fe, expandiéndose luego a Misiones, Formosa, Buenos Aires y Tucumán ${ }^{15}$.

Recibido: 15 febrero 2018 / Aceptado: 3 abril 2018

Proyecto Nacional financiado por INTA, PNSA-1115054.
La leche bubalina posee una concentración tres veces mayor de grasa butirosa y $30 \%$ más de proteínas que la leche vacuna, características que le permiten obtener un mejor rendimiento en sus derivados ${ }^{11}$.

La incorporación de diferentes subproductos y aditivos en la dieta, como los ionóforos, ha adquirido importancia en estos sistemas de producción. La monensina es un ionóforo que frecuentemente se utiliza para aumentar el rendimiento productivo, por sus efectos coccidiostáticos preventivos y terapéuticos, entre otros. La dosis de monensina recomendada para el ga- 
nado bovino es de $1-3 \mathrm{mg} / \mathrm{kg}$ de peso vivo (PV), siendo tóxica a los $20 \mathrm{mg} / \mathrm{kg} \mathrm{PV}^{3,7}$.

Los búfalos de agua (Bubalus bubalis) son más sensibles a los efectos de la monensina y la dosis tóxica es igual o mayor a $5 \mathrm{mg} / \mathrm{kg} \mathrm{PV}^{17}$. Los principales componentes orgánicos afectados en una intoxicación con monensina son los músculos cardíaco y esquelético ${ }^{5}$, pero también se han constatado lesiones en hígado y pulmón de bovinos intoxicados. La presencia o ausencia de tales lesiones dependen de la dosis ingerida ${ }^{3,17}$.

Microscópicamente los hallazgos principales son miopatías y miocardiopatías degenerativas a necrotizantes, no supurativas ${ }^{1,2,9,12,16}$. Para arribar al diagnóstico de los cuadros de intoxicación se deben tener en cuenta datos anamnésicos, signos clínicos y parámetros bioquímicos, junto con los hallazgos patológicos macro y microscópicos.

El objetivo de este trabajo fue describir por primera vez en el país los hallazgos clínicos-patológicos en búfalas con diagnóstico presuntivo de intoxicación con ionóforos.

\section{MATERIAL Y MÉTODOS}

Antecedentes. En diciembre de 2014 profesionales del Servicio de Diagnóstico Veterinario Especializado del INTA EEA Balcarce realizaron una visita a un establecimiento en el partido de Mercedes (S34 ${ }^{\circ} 44^{\prime}$ W59 ${ }^{\circ} 4^{\prime}$ ), Provincia de Buenos Aires, Argentina. El mismo contaba con un rodeo de 120 búfalas de agua de raza Mediterránea, de las cuales 50 se encontraban en ordeñe, consumiendo una pastura polifítica compuesta de festuca (Lolium arundinaceum), trébol blanco (Trifolium repens) y raigrás (Lolium perenne). Además, durante el ordeñe recibían $2 \mathrm{~kg} /$ animal de una ración comercial para suplementación de bovinos, compuesta por maíz, afrechillo de trigo, monensina al $10 \%$, pellet de soja y núcleo mineral. La ración se complementaba con $400 \mathrm{~g}$ de sales de magnesio por día.

Los animales habían sido vacunados contra enfermedades clostridiales ( 2 dosis con diferencia de 21 días) a los 6 meses de edad y desparasitados regularmente con ivermectina, según criterio veterinario. También se habían vacunado contra fiebre aftosa y carbunclo, según plan nacional vigente en coincidencia con lo recomendado para ganado bovino. Los animales en producción estaban libres de brucelosis y tuberculosis.

Problema. Ocurrió en el lote de búfalas adultas en ordeñe, donde se registró una caída del $50 \%$ en la producción lechera y la muerte de 5 búfalas, ocurrida a los 20-30 días post parto, en un lapso de 5 días.

Procedimiento. Durante la recorrida del establecimiento, se observó la pastura que los animales consumían, se recopiló información anamnésica y se inspeccionaron 5 animales seleccionados al azar del rodeo en ordeñe, y uno con signología clínica evidente. Se revisaron clínicamente (frecuencia respiratoria, temperatura rectal) y se extrajo sangre por punción yugular para evaluar la actividad sérica de las enzimas creatin-fosfokinasa (CPK) y aspartato amino transferasa (AST), utilizando kits comerciales Wiener Lab. (Rosario, Argentina).

Además, se evaluaron las concentraciones séricas de calcio y magnesio, mediante espectroscopía de absorción atómica (Perkin Elmer, USA) y de fósforo inorgánico utilizando un método colorimétrico ${ }^{6}$.

Se realizó la necropsia de una búfala que había muerto espontáneamente 4 horas antes de la visita al establecimiento. Se registraron hallazgos patológicos y se tomaron muestras de corazón, pulmón, hígado, diafragma, riñón, bazo, duodeno, colon y cerebro, los cuales fueron fijados en formol tamponado al 10\% y procesados para su posterior estudio histopatológico.

\section{RESULTADOS Y DISCUSIÓN}

Durante la recorrida del potrero se detectó una infestación (no cuantificada) de las gramíneas preponderantes con el hongo Claviceps purpurea. De las 50 búfalas en ordeñe, cinco habían manifestado depresión, disnea, sialorrea, decúbito y habían muerto espontáneamente (mortalidad del 10\%; letalidad del 100\%) en un transcurso de 5 días.

La producción diaria del rodeo en ordeñe se había visto reducida en un 47\% (de 190 a 90 litros/día) en los últimos 7 días. Un animal se encontraba clínicamente afectado $\left(\mathrm{N}^{\circ} 6\right)$ presentando elevada temperatura rectal (Tabla 1). Este parámetro también se encontró alterado en otros 5 animales del rodeo en ordeñe revisados al azar. Uno de ellos también presentó taquipnea (Tabla 1).

Las actividades de las enzimas CPK y AST se encontraron elevadas, tanto en el animal afectado clínicamente $\left(\mathrm{N}^{\circ} 6\right)$ como en los muestreados al azar. Sin embargo, la concentración de los macrominerales evaluados se encontraba dentro de los parámetros fisiológicos para la especie (Tabla 2).

La búfala adulta necropsiada presentaba un grado de autólisis 1 (escala 0 a 4). Macroscópicamente, en el miocardio se observaron múltiples áreas de coloración pálida (Figura 1A), abundante hidrotórax (dos litros aproximadamente, Figura 1B), ascitis (un litro aproximadamente) y edema entre el músculo y las fascias del diafragma, en la pared de la vesícula biliar y en el duodeno. El hígado estaba congestivo y con un puntillado hemorrágico generalizado.

En el análisis histopatológico se detectó una miocarditis degenerativa a necrotizante, severa, multifocal, con infiltrado mononuclear compuesto principalmente por macrófagos y linfocitos en menor cantidad (Figura 2A). También se observó una hepatitis necrotizante centrolobulillar severa y generalizada (Figuras $2 \mathrm{~B}$ y 2C). El parénquima pulmonar se encontraba congestivo, con edema intersticial e intra-alveolar severo, sin respuesta inflamatoria asociada. En músculo diafragmático se observó edema interfascicular e infiltrado mononuclear leve interfibrilar compuesto por macrófagos y linfocitos. 
Tabla 1. Parámetros clínicos evaluados en búfalas del rodeo afectado.

\begin{tabular}{cccc}
\hline animal & fecha parición & FR & TR \\
\hline 1 & noviembre 7 & 20 & 40,2 \\
2 & octubre 23 & 36 & 40,7 \\
3 & noviembre 8 & 28 & 40,4 \\
4 & noviembre 13 & 24 & 40,5 \\
5 & noviembre 21 & 24 & 40,6 \\
$6^{*}$ & noviembre 22 & 48 & 40,5 \\
VDR & - & $10-30$ & $38,5-39,5$ \\
\hline
\end{tabular}

VDR: valores de referencia ${ }^{4}$. FR: frecuencia respiratoria (mov./min). TR: temperatura rectal $\left(38,5-39,5^{\circ} \mathrm{C}\right)$. ${ }^{*}$ animal afectado clínicamente.

Tabla 2. Parámetros bioquímico-clínicos evaluados en búfalas del rodeo afectado.

\begin{tabular}{cccccc}
\hline animal & AST & CPK & $\mathrm{Ca}$ & $\mathrm{P}$ & $\mathrm{Mg}$ \\
\hline 1 & 230 & 5828 & 13,7 & 5,7 & 2,3 \\
2 & 380 & 1403 & 13,6 & 8,9 & 2,2 \\
3 & 500 & 10847 & 10,8 & 4,2 & 2,2 \\
4 & 230 & 836 & 10,1 & 4,5 & 1,6 \\
5 & 50 & 108 & 10,7 & 5,0 & 2,0 \\
$6^{*}$ & 1080 & 22450 & 12,0 & 6,8 & 1,7 \\
VDR & $21-121$ & $14-177$ & $8,2-14,9$ & $4,5-8,8$ & $2,0-3,9$ \\
unidad & $\mathrm{U} / 1$ & $\mathrm{U} / \mathrm{l}$ & $\mathrm{mg} / \mathrm{dl}$ & $\mathrm{mg} / \mathrm{dl}$ & $\mathrm{mg} / \mathrm{dl}$ \\
\hline
\end{tabular}

VDR: valores de referencia ${ }^{8}$. ${ }^{*}$ animal afectado clínicamente.

Los hallazgos clínico-patológicos presentes en este estudio son compatibles con los descriptos en cuadros de intoxicación crónica natural o experimental con ionóforos en diferentes especies de rumiantes ${ }^{3,5,17}$. Al no existir metodologías que permitan confirmar la presencia de ionóforos en fluidos y/o tejidos animales, el

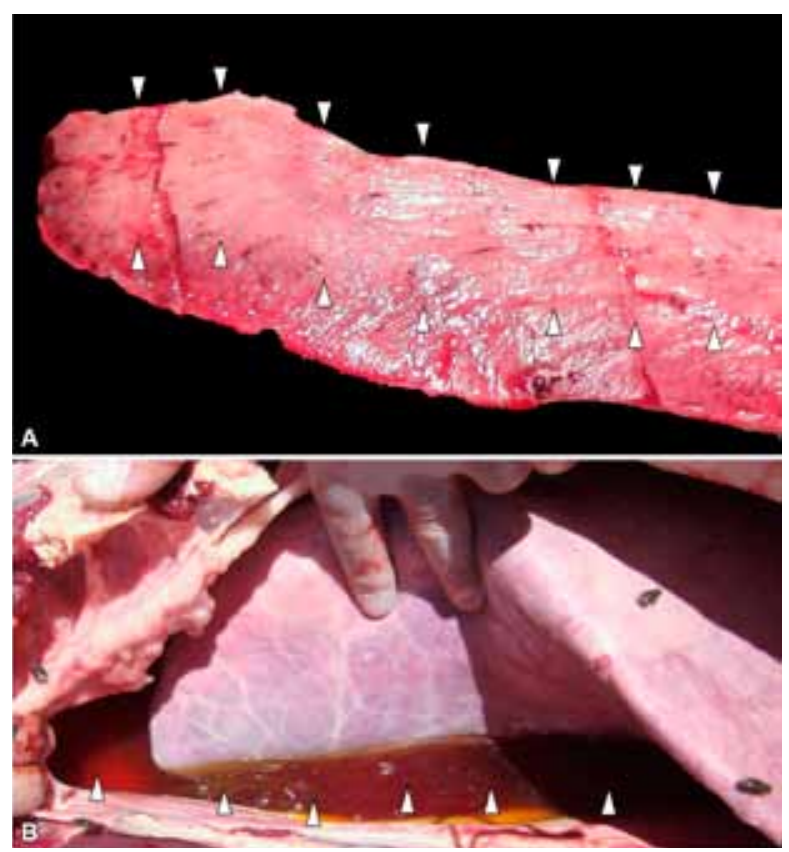

Figura 1. A: área de coloración más clara en miocardio (flechas). B: hidrotórax (flechas). diagnóstico se realizó en base a la anamnesis y a los hallazgos clínico-patológicos observados.

El hecho de que el alimento estuviera formulado para bovinos con concentraciones del $10 \%$ de monensina, y la ausencia de otros tóxicos cardíacos, nos permitió considerar a la misma como responsable de las lesiones descriptas. La muerte de los animales podría explicarse por una falla cardíaca progresiva producto de las lesiones miocárdicas ${ }^{5}$.

Los parámetros hematológicos no se ven alterados como respuesta primaria o directa a la intoxicación con ionóforos. Sin embargo, algunos cambios, como las variaciones de las enzimas CPK y AST suelen ser utilizados frecuentemente para monitorear animales presuntamente intoxicados. El aumento en la actividad de CPK indica un daño en músculo esquelético y/o cardíaco ${ }^{10}$. La elevación de AST se atribuye al daño directo y/o indirecto que ejercen los ionóforos sobre las células del corazón e hígado ${ }^{13,17}$.

La elevada actividad sérica de la enzima CPK en animales que no manifestaban signología, podrían indicar una afección subclínica de esta intoxicación. Algunas de las manifestaciones clínicas, como la elevada temperatura corporal, podrían explicarse por un cuadro de ergotismo subclínico debido a la presencia de Claviceps purpurea y la elevada temperatura ambiente en esa época del año ${ }^{14}$.

Debido a la escasa información sobre manejo productivo en búfalos, es usual extrapolar en esta especie la información existente en el ganado bovino. Sin embargo, entre ambos rumiantes existen importantes

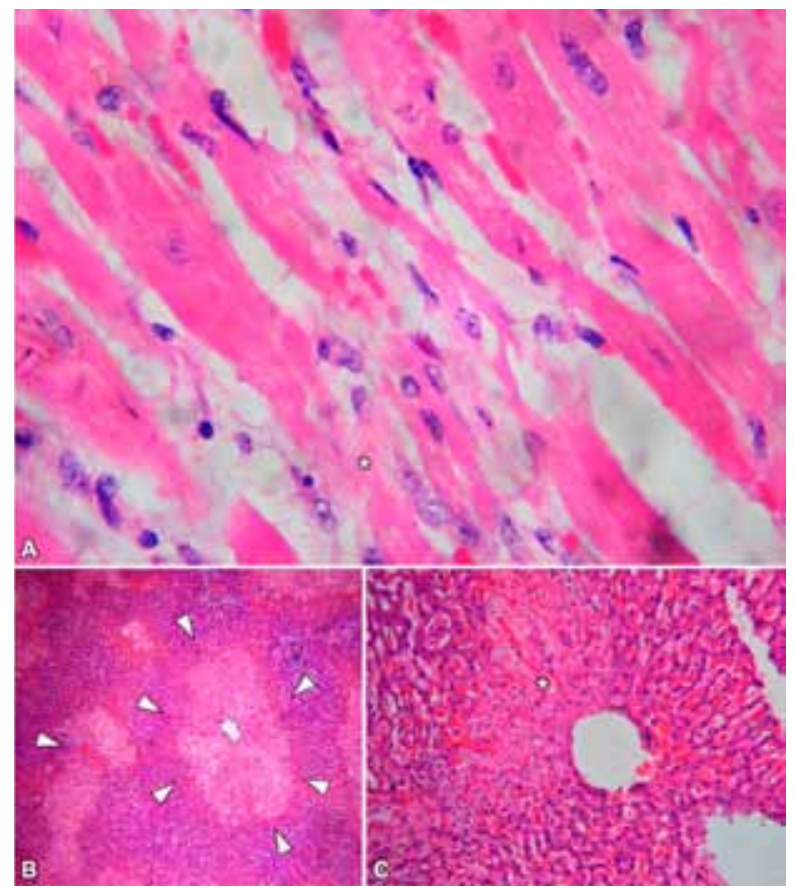

Figura 2. A: fibras miocárdicas con degeneración y necrosis $(*)$ y una respuesta inflamatoria no supurativa asociada. Hematoxilina y eosina (HE), 400x. B: hepatitis necrotizante centrolobulillar severa (flechas). HE 40x. C: detalle del área de necrosis centrolobulillar hepática $(*)$. HE 100x. 
diferencias. La producción bubalina ha aumentado en los últimos años en Argentina, por lo cual consideramos que es fundamental generar nuevos conocimientos para mejorar los aspectos productivos y/o sanitarios en esta especie, que hasta el presente son escasos.

En este trabajo queda en evidencia la mayor susceptibilidad de los bubalinos a los ionóforos, por lo tanto, es imprescindible tener en cuenta estas y otras diferencias al momento de utilizar una dieta formulada con monensina.

Agradecimientos. A Lilian Lischinsky y Mónica Drake por su participación en el procesamiento de las muestras en los laboratorios de Patología y de Bioquímica Clínica, respectivamente (INTA Balcarce, Argentina).

\section{REFERENCIAS}

1. Barros CS. 1998. Intoxicação por antibióticos ionóforos. En: Doenças de Ruminantes e Eqüinos (Riet-Correa F, Schild AL, Méndez MC, ed), Ed.Universitária, UFPel, Pelotas, Brasil, p. 462-466.

2. Barros CS. 2001. Intoxicação por antibióticos ionóforos. En: Doenças de Ruminantes e Eqüinos (Riet-Correa F, Schild AL, Méndez MC, Lemos RA, ed), Editora Varela, São Paulo, Brasil, p. 186-191.

3. Basaraba RJ, Oehme FW, Vorhies MW, Stokka GL. 1999. Toxicosis in cattle from concurrent feeding of monensin and dried distiller's grains contamined with macrolide antibiotics. $J$ Vet Diagn Invest 11: 76-86.

4. Blood DC, Radostits OM. 1992. Medicina Veterinaria, $7^{\circ}$ ed., Interamericana / McGraw-Hill, New York, p.3-38.

5. Cooper BJ, Valentine BA. 2016. Muscle and tendon. In: Jubb, Kennedy \& Palmer's Pathology of Domestic Animals, 5th ed., Elsevier, Ontario, p. 164-249.
6. Cseh S, Fay P, Sueldo R, Drake M. 1994. Una microtécnica simple para el dosaje de fósforo inorgánico en suero bovino. Rev Arg Prod Anim 14: 137-138.

7. Duffield T et al. 2002. Pre-partum monensin for the reduction of energy associated disease in postpartum cows. J Dairy Sci 85: 397-405.

8. Ellah MR, Hamed MI, Derar RI. 2014. Serum biochemical and hematological reference values for lactating buffaloes. Comp Clin Path 23: 1179-1188.

9. Hall JH. 2004. Ionophores. In: Clinical Veterinary Toxicology (Plumlee EB, Ed), Mosby, St. Louis, Missouri, USA, p. 120-127.

10. Kaneko JJ. 1989. Clinical Biochemistry of Domestic Animals, Academic Press, 4th. ed., New York, p. 886-901.

11. Mignaquy ET. 2010. El búfalo en Argentina, Secretaría de Agricultura, Ganadería, Pesca y Alimentos, Boletín Bubalino, p. 1-6.

12. Novilla MN. 1992. The veterinary importance of the toxic syndrome induced by ionophores. Vet Hum Toxicol 34: 6670 .

13. Novilla MN, Owen NV, Todd GC. 1994. The comparative toxicology of narasin in laboratory animals. Vet $\mathrm{Hu}$ man Toxicol 36: 318-323.

14. Novilla MN. 2007. Ionophores. In: Veterinary Toxicology (Gupta R., ed.), Elsevier, Amsterdam, p. 1021-1036.

15. Patiño EM, Méndez FI, Cedrés JF, Stefani GM. 2003. Caracterización de leche de búfalas mestizas en pastizales naturales de Corrientes, Argentina. Rev Arg Prod Anim 22: 199-203.

16. Pressman BC, Fahim M. 1982. Pharmacology and toxicology of the monovalent carboxylic ionophores. Ann Rev Pharm Toxicol 22: 465-490.

17. Rozza DB, Vervuert I, Kamphues J, Farias C, Driemeier D. 2007. Monensin toxicosis in water buffaloes (Bubalus bubalis). $J$ Vet Diagn Invest 18: 494-496. 